\title{
An Assessment of Comprehensive Knowledge of HIV/AIDS among Slum and Non-Slum Populations in Delhi, India
}

\author{
Pravin K. Jha1, Padum Narayan ${ }^{2 *}$, Saritha Nair ${ }^{2}$, Deepika Ganju ${ }^{3}$, Damodar Sahu², \\ Arvind Pandey ${ }^{2}$ \\ ${ }^{1}$ Centre for Study of Regional Development, Jawaharlal Nehru University, New Delhi, India \\ ${ }^{2}$ National Institute of Medical Statistics, New Delhi, India \\ ${ }^{3}$ Population Council, Delhi, India \\ Email: ${ }^{*}$ pnmbhu@gmail.com
}

Received 9 March 2015; accepted 16 June 2015; published 19 June 2015

Copyright (C) 2015 by authors and Scientific Research Publishing Inc.

This work is licensed under the Creative Commons Attribution International License (CC BY). http://creativecommons.org/licenses/by/4.0/

(c) (i) Open Access

\section{Abstract}

In order to design appropriate HIV prevention programs, it is important to examine the perception and knowledge of HIV/AIDS and methods of prevention. This article explores comprehensive knowledge of HIV/AIDS prevention methods among women and men in slum and non-slum areas in the National Capital Territory of Delhi, India. Data were drawn from the National Family Health Survey, 2005-06 (NFHS-3). The sample included 3096 women aged 15 - 49 years and 1321 men aged 15 - 54 years. Pearson Chi-square test and logistic regression analyses were conducted to examine the association between the study variables and the background characteristics of the slum and non-slum populations. Comprehensive knowledge of HIV/AIDS prevention methods was significantly lower among women and men in slum areas as compared with non-slum areas. Compared to men, women had less comprehensive knowledge of HIV/AIDS prevention methods in slum and non-slum areas, even after controlling for various demographic and socio-economic and exposure variables. Interventions are needed to build knowledge of HIV/AIDS transmission and prevention methods through mass media campaigns, and information, education and communication programs (IEC) on HIV/AIDS in slum areas.

\section{Keywords}

Slum, Knowledge, HIV/AIDS

\footnotetext{
${ }^{*}$ Corresponding author.
}

How to cite this paper: Jha, P.K., Narayan, P., Nair, S., Ganju, D., Sahu, D. and Pandey, A. (2015) An Assessment of Comprehensive Knowledge of HIV/AIDS among Slum and Non-Slum Populations in Delhi, India. Open Journal of Preventive Medicine, 5, 259-268. http://dx.doi.org/10.4236/ojpm.2015.56029 


\section{Introduction}

India, with a population of over 1.21 billion, [1] is the second most populous country in the world [2]. Around 31.2 per cent of India's population resides in urban areas, which was 27.8 per cent in 2001, witnessing 3.4 per cent increase in the share of urban population during 2001-11 [1] [3]. In absolute numbers, India has the second largest slum population after China [4] with 17.4 per cent of the urban population living in slum areas in 2011, which was about 15 per cent in 2001 [1]. Of these, around 38 per cent of the population lives in 46 million-plus cities [5]. Such unprecedented urban population growth is attributed to greater job opportunities in metro cities pulling unemployed poor people from different regions of country for employment and livelihood [5]. These migrants are often from tribal and rural communities, with a low level of education and skills. They are not able to afford the higher cost of housing in metro cities, and thereby forced to settle in slums, resulting in a high growth of the slum population [5] [6]. People living in slums are deprived of access to health and other services, making them vulnerable to opportunistic infections; moreover, many are not aware of available services, especially for diseases like HIV/AIDS [4]. The National Capital Territory (NCT) of Delhi is one state of India where about 98 per cent of the population lives in urban areas, and 15 per cent of urban households live in slums, which is about 3 per cent in India's slum population [1] [5]. While India has witnessed a decline in adult HIV prevalence during the past decade, HIV prevalence rates in Delhi have been increasing [7]. Adult HIV prevalence in Delhi was estimated at 0.18 per cent in 2007, and 0.22 per cent in 2011, against the national estimate of 0.41 per cent in 2001 and 0.27 per cent in 2011 [7]. However, there are no separate HIV prevalence estimates for the slum and non-slum population of India. A number of studies have been conducted to examine the behavioral risk factors [8]-[10] associated with HIV/AIDS, but few studies have compared the risk behaviors of slum and non-slum populations in the country. A population based study conducted in Kenya has indicated that slum population as compared to non-slum urban population was at a greater risk of HIV infection [11]. A study of migrant tribals living in urban slums in India shows that they engage in risky sexual behavior and initiate sex at an early age [8] [10]. Hence, to address the transmission of HIV in slum populations, the level of comprehensive knowledge of HIV/AIDS prevention methods and access to HIV/AIDS information and services are important issues, especially in HIV epidemic countries. UNAIDS (2008) had emphasized improving awareness and knowledge of prevention methods of HIV/AIDS as the first strategy in the battle against HIV/AIDS [12]. Globally, improving awareness and knowledge of HIV/AIDS through targeted HIV interventions for high-risk groups have succeeded in reducing new HIV infections [12].

In India, the National AIDS Control Program (NACP) focuses on enhancing HIV/AIDS awareness and knowledge through behaviour change preventive practices [13]. A study of 8 metropolitan cities including Delhi indicates that AIDS knowledge is almost 100 per cent among adult men aged 15 - 59 and 89 - 99 per cent among women aged 15 - 49, and lower among women from slum areas than non-slum areas [14]. In India studies on awareness and knowledge of HIV/AIDS and its transmission among the slum population [15]-[20], indicate that slum population have limited knowledge, myths and misconceptions [15] [19] [20] about the mode of HIV transmission [8] [14]. Evidence from India [8] [9] [14], China [21] and Ghana [22] and some West African countries [23] show that women are less knowledgeable about HIV/AIDS than men. A large cross-sectional survey shows that the percentage of women and men in Indian slums with comprehensive knowledge of HIV/AIDS prevention methods varies respectively between 22 - 61 per cent and 33 - 71 per cent [14]. The objective of this study is to examine awareness of HIV/AIDS, comprehensive knowledge of HIV prevention methods, and the factors associated with comprehensive awareness of HIV/AIDS among adult women and men in slum and non-slum areas of Delhi, India.

\section{Materials and Methods}

This study uses data from women aged 15 - 49 years and men aged 15 - 54 years in slum and non-slum areas of Delhi, India, who participated in the National Family Health Survey (NFHS-3), conducted in 2005-06 [8] [24]. NFHS-3 provides information on HIV prevalence, attitudes toward HIV/AIDS patients, high-risk sexual behavior, and HIV knowledge among the slum and non-slum population in Delhi, and other cities of India [14] [24]. In NFHS-3, people in slum and non-slum areas were asked specific questions related to awareness and knowledge of HIV/AIDS and its prevention methods, e.g. it is possible to reduce the chances of getting HIV/ AIDS by abstaining from sex, having just one uninfected and faithful sex partner who has no other sex partners, and using a condom during every act of sexual intercourse [24]. A two-stage sampling procedure was used to select 
households from slum and non-slum areas in Delhi. In the first stage, slum and non-slum Census Enumeration Blocks (CEBs) were independently selected, which subsequently served as two separate sampling frames. In the second stage, households were selected from each sampling frame using probability proportional to size sampling (PPS). In Delhi, 2000 households were selected from the enumeration areas designated as slum and non-slum areas within the Municipal Corporation city limits, separately [24].

\section{Measures}

\subsection{Outcome Variable}

The outcome variable in this study was comprehensive knowledge of HIV/AIDS of prevention methods, measured by correct answers to HIV transmission modes and HIV prevention methods. This variable was constructed based on the ability to correctly identify three major ways of preventing HIV (Questions 1 - 3 below), awareness that a healthy looking person can have HIV (Question 4 below), and to reject the two most common misconceptions about HIV transmission (Question 5 below) [14].

1) Using a condom for every act of sexual intercourse

2) Limiting sexual intercourse to just one uninfected faithful partner

3) Abstaining from sexual intercourse

4) Aware that a healthy looking person can have HIV/AIDS, and

5) HIV/AIDS can be transmitted through mosquito bites and by sharing food with a person who has HIV/ AIDS.

A respondent was considered to have comprehensive knowledge of HIV/AIDS prevention methods if s/he responded positively (yes) to Questions 1 - 4 and responded negatively (No) to question number 5. The indicator was dichotomized as did not have comprehensive knowledge of HIV/AIDS prevention methods (coded as 0 ) and have comprehensive knowledge of HIV/AIDS prevention methods (coded as 1).

\subsection{Independent Variables}

Socio-demographic and economic characteristics included age, education, marital status, occupation, age at first intercourse, alcohol consumption, media exposure, prior HIV testing and wealth index. The wealth index constructed in NFHS-3 has been used in the study. In NFHS-3, the wealth index was constructed on the basis of 33 assets and housing characteristics using principal components analysis [8].

Age was measured as a continuous variable and grouped into three categories: 15 - 24, 25 - 34, and 35 years or older. Education was divided into three categories: no education, completed less than 10 years of education, completed 10 or more years of education. Marital status was categorized as never married (including return marriage not performed), and ever married (including currently married and widow/divorced/separated/deserted). Occupation was categorized as not working, and working. Media exposure was grouped into three categories: no exposure (did not read newspapers or magazines, watch TV, listen to the radio and visit the cinema/theatre at least once a week); partial exposure (read newspapers or magazines, or watched TV, or listened to the radio, or visit the cinema/theatre at least once a week); and regular exposure (read newspapers or magazines, watched TV, listened to the radio and visited the cinema/theater at least once a week). Wealth index was subdivided into the following five categories: poorest, poorer, middle, richer, and richest.

\subsection{Statistical Analysis}

State weights were used to correct oversampling and to maintain the representativeness of the data as well as the statistical soundness of indicators calculated based on these data at the city level and also for slum and non-slum areas within the city [24]. Pearson Chi-square test and logistic regression were used to examine statistical significance of association between comprehensive knowledge of HIV/AIDS prevention methods and the background characteristics of women and men in slum and non-slum areas. In logistic regression, no comprehensive knowledge of HIV/AIDS prevention methods (coded as 0) was assigned as the reference category. In the case of media exposure and the wealth index variables, partial media exposure and the middle wealth category were respectively used as the reference category for calculating adjusted odds ratios, due to the small number of observations in the no media exposure group (in the media exposure variable) and the poorest and poorer groups (in the wealth index). In this study, SPSS-20 was used to analyze the data. 


\section{Results}

\subsection{Awareness of HIV/AIDS}

Of the 4417 respondents included in the analysis, 3096 were women and 1321 were men; of these, 90 per cent of women and 98 per cent of men had heard of HIV/AIDS (Table 1). Overall, more women and men in non-slum than slum areas were aware of HIV/AIDS. In slum areas, a higher percentage of younger than older women were aware of HIV/AIDS; however a reverse pattern was observed in non-slum areas (Table 1). In slum and non-slum areas, HIV/AIDS awareness among women increased with education level. Among men, HIV/AIDS awareness was higher among those aged 25 - 34 years in slum areas, and less than 25 years in non-slum areas. The percentage of uneducated men aware of HIV/AIDS was higher in slum than non-slum areas. In both slum and non-slum areas, a larger percentage of never married than ever married women were aware of HIV/AIDS. Similarly, HIV/AIDS awareness was higher among never married than ever married men in slum and non-slum areas.

Awareness of HIV/AIDS in slum areas was highest among women who never had sex, while in non-slum areas, awareness was highest among women who had experienced first sex after age 20 years. While awareness was high among men who never experienced sex in slum as well as non-slum areas, awareness was higher in non-slum than slum areas. In slum and non-slum areas, HIV/AIDS awareness was higher among men who did not drink alcohol than others. Among women and men with regular media exposure, awareness of HIV/AIDS was high in both locations. The highest proportion of women and men from the richest wealth group in both slum and non-slum areas were aware of HIV. However, awareness was highest among women and men from the middle wealth category in slum as compared to non-slum areas.

\subsection{Comprehensive Knowledge of HIV/AIDS Prevention Methods}

Comprehensive knowledge of HIV/AIDS prevention methods was significantly lower among women and men in slum areas than non-slum areas respectively (women: $\chi^{2}=43.32, \mathrm{df}=2, \mathrm{p}<0.05$ and men: $\chi^{2}=4.74, \mathrm{df}=2, \mathrm{p}$ $<0.05$ ). Comprehensive knowledge of HIV/AIDS prevention methods was lower among women than men in both slum and non-slum areas (Table 2). For most indicators, comprehensive knowledge of prevention methods was lower among women in slum areas than non-slum areas, except for uneducated women and those in the middle wealth category. In both slum and non-slum areas, comprehensive knowledge of HIV/AIDS prevention methods was high among women who were educated (more than 10 years education), never married, working, had first sex after age 20, had regular media exposure, and were from the richest wealth category. Among men, comprehensive knowledge of prevention methods was high in the younger group (less than 25 years) in slum areas, and in the older group (aged 35 years or more) in non-slum areas. Further, comprehensive knowledge of prevention methods was lower in non-slum areas as compared to slum areas among men with high educational levels (10 years or more education), those not working, who never had sex, with partial media exposure, and from the richest, richer, and poorer wealth groups.

\subsection{Predictors of Comprehensive Knowledge of HIV/AIDS Prevention Methods}

Logistic regression analysis show that comprehensive knowledge of prevention methods was significantly higher among women in non-slum areas than slum areas (OR: 1.98, 95\%CI $(1.61-2.44), \mathrm{p}<0.05)$ and similarly higher among men in non-slum areas compared to men in slum areas (OR: 1.29, 95\%CI (0.10 - 1.69), p = 0.06).

The predictors of comprehensive HIV/AIDS prevention methods were similar for women across slum and non-slum settings. As seen in Table 3, in both slum and non-slum areas educated women were significantly more likely than uneducated women to have comprehensive knowledge of HIV/AIDS prevention methods. Further, the likelihood of having comprehensive knowledge of HIV/AIDS prevention methods was higher among working women as compared to non-working women in both slum and non-slum areas. Ever married women were less likely than never married women in slum and non-slum areas to have comprehensive knowledge of HIV/AIDS prevention methods. Women who never experienced sex were less likely than others to have comprehensive knowledge of HIV/AIDS prevention methods in slum and non-slum areas. Women with regular media exposure were significantly more likely to have comprehensive knowledge of HIV/AIDS prevention methods compared to women with partial media exposure in both slum and non-slum areas (slum-AOR: 1.50, 95\%CI (1.05 - 2.14), $\mathrm{p}<0.05$; non-slum-AOR: 1.58, 95\%CI (1.03 - 2.43), $\mathrm{p}<0.05)$ ). Women who had ever 
Table 1. Awareness of HIV/AIDS among Women and Men in Slum and Non-slum Areas, Delhi, 2005-06-

\begin{tabular}{|c|c|c|c|c|c|c|c|c|c|c|c|c|}
\hline \multirow{3}{*}{$\begin{array}{l}\text { Background } \\
\text { Characteristics }\end{array}$} & \multicolumn{6}{|c|}{ Women (15 - 49 years) } & \multicolumn{6}{|c|}{ Men (15 - 54 years) } \\
\hline & \multicolumn{2}{|c|}{ Slum } & \multicolumn{2}{|c|}{ Non-slum } & \multicolumn{2}{|c|}{ Total } & \multicolumn{2}{|c|}{ Slum } & \multicolumn{2}{|c|}{ Non-slum } & \multicolumn{2}{|c|}{ Total } \\
\hline & $\mathrm{N}$ & $\%$ & $\mathrm{~N}$ & $\%$ & $\mathrm{~N}$ & $\%$ & $\mathrm{~N}$ & $\%$ & $\mathrm{~N}$ & $\%$ & $\mathrm{~N}$ & $\%$ \\
\hline Total & 572 & 80.95 & 2524 & 92.10 & 3096 & 90.04 & 282 & 95.87 & 1040 & 98.01 & 1321 & 97.55 \\
\hline \multicolumn{13}{|l|}{ Age (years) } \\
\hline$<25$ & 229 & 85.94 & 872 & 91.85 & 1101 & 90.62 & 121 & 96.51 & 388 & 99.33 & 509 & 98.66 \\
\hline $25-34$ & 178 & 79.60 & 772 & 91.12 & 950 & 88.96 & 79 & 97.32 & 312 & 97.93 & 390 & 97.80 \\
\hline$\leq 35$ & 165 & 75.47 & 880 & 93.22 & 1044 & 90.42 & 82 & 93.55 & 340 & 96.58 & 422 & 95.99 \\
\hline \multicolumn{13}{|l|}{ Education (years) } \\
\hline No education & 253 & 63.43 & 390 & 65.80 & 643 & 64.87 & 52 & 85.86 & 78 & 83.33 & 130 & 84.35 \\
\hline$<10$ & 185 & 91.14 & 578 & 90.55 & 762 & 90.69 & 146 & 97.10 & 287 & 97.75 & 433 & 97.53 \\
\hline$\leq 10$ & 134 & 100.00 & 1557 & 99.27 & 1690 & 99.32 & 84 & 100.00 & 675 & 99.81 & 758 & 99.83 \\
\hline \multicolumn{13}{|l|}{ Marital status } \\
\hline Never married & 148 & 92.04 & 694 & 94.88 & 842 & 94.38 & 116 & 96.80 & 467 & 98.89 & 583 & 98.48 \\
\hline Ever married & 424 & 77.08 & 1829 & 91.05 & 2253 & 88.42 & 166 & 95.22 & 573 & 97.29 & 739 & 96.83 \\
\hline \multicolumn{13}{|l|}{ Occupation } \\
\hline Not working & 428 & 82.80 & 1961 & 92.49 & 2389 & 90.76 & 35 & 95.52 & 206 & 98.74 & 241 & 98.27 \\
\hline Working & 144 & 75.44 & 560 & 90.93 & 704 & 87.77 & 246 & 95.91 & 830 & 97.82 & 1076 & 97.38 \\
\hline \multicolumn{13}{|l|}{$\begin{array}{c}\text { Age at first } \\
\text { intercourse(years) }\end{array}$} \\
\hline Not had intercourse & 148 & 92.04 & 693 & 94.87 & 841 & 94.37 & 92 & 95.98 & 397 & 98.70 & 489 & 98.19 \\
\hline$<16$ & 133 & 67.31 & 282 & 81.08 & 415 & 76.67 & 5 & 100.00 & 5 & 100.00 & 10 & 100.00 \\
\hline $16-20$ & 224 & 79.50 & 873 & 88.81 & 1098 & 86.90 & 29 & 96.30 & 69 & 98.11 & 97 & 97.58 \\
\hline$>20$ & 66 & 88.46 & 675 & 98.12 & 742 & 97.25 & 157 & 95.61 & 569 & 97.50 & 725 & 97.09 \\
\hline \multicolumn{13}{|l|}{ Drinks alcohol } \\
\hline Yes & nc & nc & nc & nc & nc & nc & 97 & 94.02 & 349 & 97.41 & 446 & 96.67 \\
\hline No & nc & nc & nc & nc & nc & nc & 185 & 96.85 & 690 & 98.31 & 875 & 98.01 \\
\hline \multicolumn{13}{|l|}{ Media exposure } \\
\hline No exposure & 46 & 43.82 & 75 & 42.37 & 120 & 42.92 & 6 & 66.67 & 3 & 50.00 & 9 & 61.84 \\
\hline Partial exposure & 106 & 69.71 & 174 & 72.26 & 280 & 71.29 & 56 & 90.48 & 101 & 89.74 & 156 & 90.00 \\
\hline Regular exposure & 420 & 87.82 & 2275 & 95.26 & 2695 & 94.10 & 220 & 98.08 & 936 & 99.03 & 1156 & 98.85 \\
\hline \multicolumn{13}{|l|}{ Prior HIV testing } \\
\hline Never tested & 558 & 80.48 & 2337 & 91.47 & 2895 & 89.35 & 276 & 95.79 & 984 & 97.90 & 1260 & 97.43 \\
\hline Ever tested & 14 & 100.00 & 187 & 100.00 & 200 & 100.00 & 6 & 100.00 & 56 & 100.00 & 61 & 100.00 \\
\hline \multicolumn{13}{|l|}{ Wealth index } \\
\hline Poorest & 3 & 40.00 & 0 & 0.00 & 3 & 40.00 & 3 & 80.00 & 0 & 0.00 & 3 & 80.00 \\
\hline Poorer & 30 & 51.72 & 23 & 33.33 & 53 & 43.72 & 21 & 76.92 & 21 & 87.50 & 41 & 82.22 \\
\hline Middle & 140 & 61.90 & 51 & 52.50 & 190 & 59.40 & 72 & 93.43 & 32 & 88.00 & 105 & 91.76 \\
\hline Richer & 177 & 83.86 & 302 & 75.21 & 480 & 78.41 & 89 & 98.81 & 164 & 96.06 & 253 & 97.03 \\
\hline Richest & 222 & 94.94 & 2148 & 96.04 & 2371 & 95.94 & 97 & 99.46 & 822 & 99.06 & 920 & 99.10 \\
\hline
\end{tabular}

nc-not calculated due to small number of observations. 
Table 2. Comprehensive Knowledge of HIV/AIDS Prevention Methods among Women and Men in Slum and Non-slum Areas, Delhi, 2005-06.

\begin{tabular}{|c|c|c|c|c|c|c|c|c|c|c|c|c|}
\hline \multirow{3}{*}{$\begin{array}{l}\text { Background } \\
\text { Characteristics }\end{array}$} & \multicolumn{6}{|c|}{ Women (15 - 49 years) } & \multicolumn{6}{|c|}{ Men (15 - 54 years) } \\
\hline & \multicolumn{2}{|c|}{ Slum } & \multicolumn{2}{|c|}{ Non-slum } & \multicolumn{2}{|c|}{ Total } & \multicolumn{2}{|c|}{ Slum } & \multicolumn{2}{|c|}{ Non-slum } & \multicolumn{2}{|c|}{ Total } \\
\hline & $\mathrm{N}$ & $\%$ & $\mathrm{~N}$ & $\%$ & $\mathrm{~N}$ & $\%$ & $\mathrm{~N}$ & $\%$ & $\mathrm{~N}$ & $\%$ & $\mathrm{~N}$ & $\%$ \\
\hline Total & 463 & 36.5 & 2325 & 53.25 & 2788 & 50.48 & 270 & 54.07 & 1018 & 60.41 & 1289 & 59.12 \\
\hline \multicolumn{13}{|l|}{ Age (years) } \\
\hline$<25$ & 197 & 36.10 & 801 & 54.04 & 998 & 50.50 & 117 & 53.85 & 385 & 53.02 & 502 & 53.21 \\
\hline $25-34$ & 142 & 36.82 & 703 & 51.44 & 845 & 48.99 & 77 & 60.69 & 305 & 63.56 & 382 & 62.98 \\
\hline$\leq 35$ & 124 & 36.63 & 820 & 54.02 & 944 & 51.74 & 77 & 48.28 & 328 & 66.14 & 405 & 62.76 \\
\hline \multicolumn{13}{|l|}{ Education (years) } \\
\hline No education & 161 & 22.93 & 256 & 20.30 & 417 & 21.31 & 45 & 32.94 & 65 & 36.00 & 110 & 34.75 \\
\hline$<10$ & 168 & 34.95 & 523 & 35.92 & 691 & 35.69 & 142 & 50.37 & 281 & 48.39 & 422 & 49.05 \\
\hline$\leq 10$ & 134 & 54.58 & 1545 & 64.59 & 1679 & 63.79 & 84 & 72.15 & 674 & 67.75 & 757 & 68.24 \\
\hline \multicolumn{13}{|l|}{ Marital status } \\
\hline Never married & 136 & 40.98 & 659 & 55.30 & 795 & 52.85 & 112 & 56.13 & 462 & 56.58 & 574 & 56.49 \\
\hline Ever married & 327 & 34.59 & 1666 & 52.44 & 1992 & 49.51 & 158 & 52.84 & 557 & 63.57 & 715 & 61.20 \\
\hline \multicolumn{13}{|l|}{ Occupation } \\
\hline Not working & 354 & 35.21 & 1814 & 51.85 & 2169 & 49.13 & 34 & 60.94 & 203 & 56.69 & 237 & 57.30 \\
\hline Working & 108 & 40.57 & 509 & 58.35 & 618 & 55.23 & 236 & 53.14 & 812 & 61.31 & 1048 & 59.47 \\
\hline \multicolumn{13}{|l|}{$\begin{array}{c}\text { Age at first } \\
\text { intercourse (years) }\end{array}$} \\
\hline Not had intercourse & 136 & 40.98 & 658 & 55.21 & 794 & 52.77 & 88 & 55.09 & 392 & 54.46 & 480 & 54.57 \\
\hline$<16$ & 89 & 24.00 & 229 & 30.56 & 318 & 28.71 & 5 & 77.78 & 5 & 50.00 & 10 & 63.31 \\
\hline $16-20$ & 178 & 34.10 & 776 & 46.64 & 954 & 44.30 & 28 & 50.00 & 67 & 67.31 & 95 & 62.28 \\
\hline$>20$ & 59 & 52.17 & 663 & 66.86 & 722 & 65.66 & 150 & 53.71 & 555 & 63.87 & 704 & 61.71 \\
\hline \multicolumn{13}{|l|}{ Drinks alcohol } \\
\hline Yes & nc & nc & nc & nc & nc & nc & 179 & 55.62 & 679 & 61.33 & 858 & 60.14 \\
\hline No & nc & nc & nc & nc & nc & nc & 91 & 51.45 & 340 & 58.56 & 432 & 57.05 \\
\hline \multicolumn{13}{|l|}{ Media exposure } \\
\hline No Exposure & 20 & 20.51 & 32 & 16.00 & 52 & 17.74 & 4 & 25.00 & 1 & 100.00 & 6 & 42.56 \\
\hline Partial exposure & 74 & 24.83 & 126 & 31.31 & 200 & 28.91 & 50 & 43.16 & 91 & 42.86 & 141 & 42.96 \\
\hline Regular exposure & 369 & 39.67 & 2167 & 55.07 & 2536 & 52.83 & 216 & 57.35 & 927 & 62.06 & 1143 & 61.17 \\
\hline \multicolumn{13}{|l|}{ Prior HIV testing } \\
\hline Never tested & 449 & 35.31 & 2138 & 51.48 & 2587 & 48.68 & 264 & 54.60 & 963 & 60.00 & 1228 & 58.84 \\
\hline Ever tested & 14 & 74.07 & 187 & 73.47 & 200 & 73.51 & 6 & 36.36 & 56 & 67.44 & 61 & 64.50 \\
\hline \multicolumn{13}{|l|}{ Wealth index } \\
\hline Poorest & 1 & & 0 & & 1 & & 2 & 50.00 & & & 2 & 50.00 \\
\hline Poorer & 15 & 6.67 & 8 & 16.67 & 23 & 9.98 & 16 & 56.67 & 18 & 28.57 & 34 & 41.69 \\
\hline Middle & 86 & 27.22 & 27 & 19.05 & 113 & 25.29 & 68 & 44.53 & 28 & 59.09 & 96 & 48.84 \\
\hline Richer & 149 & 28.18 & 227 & 29.05 & 376 & 28.71 & 88 & 50.60 & 158 & 46.72 & 246 & 48.11 \\
\hline Richest & 211 & 48.43 & 2063 & 56.49 & 2274 & 55.74 & 97 & 63.93 & 815 & 63.81 & 911 & 63.82 \\
\hline
\end{tabular}

nc-not calculated due to small number of observations. 
Table 3. Association between Women's and Men's Background Characteristics and Comprehensive Knowledge of HIV/ AIDS Prevention Methods in Slum and Non-slum Areas, Delhi, 2005-06-

\begin{tabular}{|c|c|c|c|c|c|c|c|c|}
\hline \multirow{4}{*}{$\begin{array}{l}\text { Background } \\
\text { Characteristics }\end{array}$} & \multicolumn{8}{|c|}{ Comprehensive Knowledge of HIV } \\
\hline & \multicolumn{4}{|c|}{ Women (15 - 49 years) } & \multicolumn{4}{|c|}{ Men (15 - 54 years) } \\
\hline & \multicolumn{2}{|l|}{ Slum } & \multicolumn{2}{|l|}{ Non-slum } & \multicolumn{2}{|l|}{ Slum } & \multicolumn{2}{|l|}{ Non-slum } \\
\hline & AOR (95\% CI) & $\mathbf{P}$ & AOR $(95 \% \mathrm{CI})$ & $\mathbf{P}$ & AOR (95\% CI) & $\mathbf{P}$ & AOR (95\% CI) & $\mathbf{P}$ \\
\hline \multicolumn{9}{|l|}{ Age (years) } \\
\hline$<25^{*}$ & 1 & & 1 & & 1 & & 1 & \\
\hline $25-34$ & $0.83(0.64-1.09)$ & 0.18 & $0.79(0.58-1.07)$ & 0.13 & $1.11(0.45-2.72)$ & 0.81 & $1.54(0.99-2.41)$ & 0.06 \\
\hline$\leq 35$ & $1.03(0.78-1.37)$ & 0.82 & $1.01(0.74-1.39)$ & 0.93 & $0.91(0.34-2.45)$ & 0.85 & $1.78(1.03-3.07)$ & 0.04 \\
\hline \multicolumn{9}{|l|}{ Education (years) } \\
\hline No education* & 1 & & 1 & & 1 & & 1 & \\
\hline$<10$ & $1.72(1.26-2.36)$ & 0 & $1.85(1.26-2.71)$ & 0 & $2.00(0.89-4.48)$ & 0.09 & $2.08(1.09-3.97)$ & 0.03 \\
\hline$\geq 10$ & 4.14 (3.01 - 5.69) & 0 & $4.69(3.22-6.82)$ & 0 & $4.55(1.82-11.38)$ & 0 & $3.87(2.03-7.40)$ & 0 \\
\hline \multicolumn{9}{|l|}{ Marital status } \\
\hline Never married ${ }^{*}$ & 1 & & 1 & & 1 & & 1 & \\
\hline Ever married & $0.75(0.08-7.29)$ & 0.81 & $0.74(0.08-7.18)$ & 0.8 & $1.04(0.31-3.46)$ & 0.95 & $0.66(0.32-1.34)$ & 0.25 \\
\hline \multicolumn{9}{|l|}{ Occupation } \\
\hline Not working* & 1 & & 1 & & 1 & & 1 & \\
\hline Working & $1.29(1.05$ - 1.58) & 0.02 & $1.23(0.98-1.53)$ & 0.07 & $0.72(0.30-1.73)$ & 0.46 & $0.91(0.60-1.37)$ & 0.64 \\
\hline \multicolumn{9}{|l|}{$\begin{array}{c}\text { Age at first } \\
\text { intercourse (years) }\end{array}$} \\
\hline $\begin{array}{l}\text { Not had sexual } \\
\text { intercourse }^{*}\end{array}$ & 1 & & 1 & & 1 & & 1 & \\
\hline$<16$ & $1.05(0.11-10.35)$ & 0.97 & $1.06(0.11-10.55)$ & 0.96 & $3.92(0.32-47.72)$ & 0.28 & $2.43(0.35-17.05)$ & 0.37 \\
\hline $16-20$ & $1.36(0.14-13.18)$ & 0.79 & $1.40(0.14-13.63)$ & 0.77 & $1.23(0.42-3.65)$ & 0.7 & $2.70(1.36-5.33)$ & 0 \\
\hline$>20$ & $1.82(0.19-17.77)$ & 0.61 & $1.84(0.19$ - 18.07) & 0.6 & $1.19(0.34-4.15)$ & 0.78 & $1.82(0.88-3.76)$ & 0.1 \\
\hline \multicolumn{9}{|l|}{ Drinks slcohol } \\
\hline $\mathrm{No}^{*}$ & & & & & 1 & & 1 & \\
\hline Yes & nc & nc & nc & nc & $0.86(0.47-1.57)$ & 0.62 & $0.89(0.68-1.16)$ & 0.02 \\
\hline \multicolumn{9}{|l|}{ Media exposure } \\
\hline Partial exposure* & 1 & & 1 & & 1 & & 1 & \\
\hline Regular exposure & $1.50(1.05-2.14)$ & 0.02 & $1.58(1.03-2.43)$ & 0.04 & $1.52(0.73-3.18)$ & 0.26 & $1.16(0.69-1.95)$ & 0.57 \\
\hline \multicolumn{9}{|l|}{ Prior HIV testing } \\
\hline Never tested ${ }^{*}$ & 1 & & 1 & & 1 & & 1 & \\
\hline Ever tested & $2.09(1.47-2.98)$ & 0 & $2.0(1.39-2.88)$ & 0 & $0.28(0.04-1.76)$ & 0.17 & $0.93(0.51-1.70)$ & 0.81 \\
\hline \multicolumn{9}{|l|}{ Wealth index } \\
\hline Middle $^{*}$ & 1 & & 1 & & 1 & & 1 & \\
\hline Richer & $0.71(0.42-1.21)$ & 0.62 & $0.89(0.30-2.63)$ & 0.88 & $0.99(0.49-2.00)$ & 0.99 & $0.43(0.17-1.05)$ & 0.06 \\
\hline Richest & $1.08(0.65-1.78)$ & 0.77 & $1.34(0.47-3.83)$ & 0.58 & $1.25(0.59-2.64)$ & 0.57 & $0.58(0.24-1.41)$ & 0.23 \\
\hline
\end{tabular}

AOR-adjusted odds ratios; P-p-value; "-reference category; nc-not calculated due to small number of observations; Middle includes poorer + poorest. 
tested for HIV were significantly more likely than those who had never tested for HIV in slum and non-slum areas-respectively, $2.09(\mathrm{p}<0.05)$ and $2.00(\mathrm{p}<0.05)$ - to have comprehensive knowledge of HIV/AIDS prevention methods. Further women from the richest wealth category were more likely to have comprehensive knowledge of HIV/AIDS prevention measures than the reference category in both slum and non-slum areas.

Results are mixed with regard to the predictors of comprehensive knowledge of HIV/AIDS prevention methods among men. Older men (above age 34 years) in non-slum areas were significantly more likely to have comprehensive knowledge of HIV/AIDS prevention methods than the reference category ( $\leq 35$ years-AOR: 1.78, 95\%CI (1.03 - 3.07), $\mathrm{p}<0.05$ ). Educated men were significantly more likely to have comprehensive knowledge of HIV/AIDS prevention methods than uneducated in non-slum areas. Ever married men were more likely to have comprehensive knowledge than never married men in slum areas; however, in non-slum areas, ever married men were less likely to have comprehensive knowledge than others. Working men in slum and non-slum areas were less likely than non-working men to have comprehensive knowledge of HIV/AIDS prevention methods. Further, in non-slum areas men who had first sex between age 16 - 20 years were more likely than men who had never had sex to have comprehensive knowledge of prevention methods; however, in slum areas, men who had first sex before age 16 were more likely to have comprehensive knowledge of HIV/AIDS prevention methods than men who had never sex.

\section{Discussion}

Findings of this study show that comprehensive knowledge of HIV/AIDS prevention methods is not as high as HIV/AIDS awareness among both women and men in slum and non-slum areas. Further, the study shows that comprehensive knowledge of HIV/AIDS prevention methods was significantly lower among women and men in slum areas than in non-slum areas. Studies in Sub-Saharan African countries have attributed low knowledge of modes of HIV transmission and prevention methods [11] [22] [25] as one of the reason of high HIV prevalence in slum compared to non-slum areas [11]; however, knowledge of modes of HIV transmission. A large cross-sectional survey shows that comprehensive knowledge of HIV/AIDS prevention methods among women and men in Indian slums varies (22 - 61 per cent for women and 33 - 71 per cent for men) [14]. For most indicators, comprehensive knowledge of HIV/AIDS prevention methods was lower among women in slum than non-slum areas, apart from uneducated and middle wealth category women. However, among men with a high level of education (10 years or more), not working, never experienced sexual intercourse, partially exposed to media, and from the richest, richer and poorer wealth groups, the percentage of comprehensive knowledge of prevention methods was low in non-slum areas as compared to slum areas. This study suggests that education is positively associated with comprehensive knowledge of HIV prevention methods; educated women and men are more likely to have comprehensive knowledge of prevention methods in both slum and non-slum areas. The likelihood of having comprehensive knowledge of prevention methods was less among ever married women in slum and non-slum areas and among ever married men in non-slum areas; however, ever married men in slum areas had higher comprehensive knowledge of prevention methods than those never married. Women who had never experienced sexual intercourse are less likely to have comprehensive knowledge of preventive methods; women who had first sexual intercourse after age 20 had a higher likelihood of comprehensive knowledge of prevention methods in slum and non-slum areas, whereas the likelihood of comprehensive knowledge of HIV/AIDS prevention methods was higher among men who had experienced first sexual intercourse before the age of 16 years in slum areas and between the age of $16-20$ years in non-slum areas. Women and men who were exposed to media regularly were more likely to have comprehensive knowledge of prevention methods of HIV/AIDS in slum and non-slum areas than others. Women belonging to the richest wealth category had a higher likelihood of comprehensive knowledge of prevention methods in slum and non-slum areas than others.

The low level of comprehensive knowledge of preventive methods of HIV/AIDS in slum areas is a cause for concern because heterosexual unprotected sex is still the primary mode of HIV transmission in India [26] [27] and slum people also engage in unprotected sex and multiple partner sex [10]. In addition, men sometimes migrate to cities without their spouse, and have unprotected sex with unpaid partners or paid sex workers, playing a bridging role in transmitting HIV infection their spouse [28]. People living in slum areas often have poor access to services, and lack awareness about available services, especially in the case of stigmatizing diseases like HIV [4]. The importance of education in halting and reducing the HIV epidemic in the slum areas is recognized. 


\section{Conclusion}

The study findings highlight that while awareness of HIV/AIDS is near-universal, comprehensive knowledge of preventive methods of HIV/AIDS is still low among women and men in both slum and non-slum areas of Delhi. People in slum areas, especially women have lower comprehensive knowledge of HIV/AIDS prevention methods as compared to those in non-slum areas. Although HIV prevention programs in India have been making extensive use of the mass media, especially the electronic media, to build awareness of HIV/AIDS prevention methods, low levels of HIV/AIDS awareness suggests a lapse in educational campaigns in building knowledge of HIV prevention. The study findings suggest that to reduce HIV/AIDS vulnerability among women and men in slum and non-slum areas, programs must focus on appropriate behaviour change communication and build awareness to educate them on HIV/AIDS prevention methods especially among women in the reproductive age group in slum areas. It is expected that this study will help to adress some of the gaps in the implementation of HIV targeted interventions in the slum and non-slum areas of India.

\section{Acknowledgements}

This paper was written as part of the Knowledge Network Project of the Population Council, which is a grantee of the Bill \& Melinda Gates Foundation through Avahan-the India AIDS Initiative. The views expressed herein are those of the authors and do not necessarily reflect the official policy or position of the Bill \& Melinda Gates Foundation and Avahan.

\section{References}

[1] Office of Registrar General and Census Commissioner (2011) Final Population Totals. Office of Registrar General and Census Commissioner, New Delhi.

[2] US Census Bureau, Demographic Internet Staff (2011) United States Census Bureau—International Data Base (IDB). www.Census.gov

[3] Office of Registrar General and Census Commissioner (2011) Rural Urban Distribution, Provisional Population Totals, 2011. Office of Registrar General and Census Commissioner, New Delhi.

[4] United Nations Human Settlements Programme (UN-HABITAT) (2012) The State of the World's Cities Report 2012/2013: Prosperity of Cities.

[5] Office of Registrar General and Census Commissioner (2011) Primary Census Abstract for Slum, 2011. Office of Registrar General and Census Commissioner, New Delhi.

[6] Babu, B.V., Swain, B.K., Mishra, S. and Kar. S.K. (2010) Primary Health Care Services among a Migrant Indigenous Population Living in an Eastern Indian City. Journal of Immigrant and Minority Health, 12, 53-59. http://dx.doi.org/10.1007/s10903-008-9181-z

[7] National AIDS Control Organization (2012) Technical Report India HIV Estimates-2012. National Institute of Medical Statistics, ICMR \& NACO, DAC, Ministry of Health \& Family Welfare, New Delhi.

[8] International Institute for Population Sciences (IIPS) and Macro International (2007) National Family Health Survey (NFHS-3), 2005-06. Vol. I, India.

[9] Singh, S.K., Parasuraman, S. and Agrahari, K. (2010) A Profile of HIV Infected Persons in India. National Family Health Survey (NFHS-3), India, 2005-06. International Institute for Population Sciences, Mumbai, ICF Macro, Calverton.

[10] Mishra, S., Swain, B.K. and Babu, B.V. (2008) Sexual Risk Behaviour among Migrant Tribal Living in Urban Slums of an Eastern Indian City: Implications on the Spread of HIV. Collegium Antropologicum, 32, 1-4.

[11] Madise, N.J., Ziraba, A.K., Inungu, J., Khamadi, S.A., Ezeh, A., Zulu, E.M., Kebaso, J., Okoth, V. and Mwaud, M. (2012) Are Slum Dwellers at Heightened Risk of HIV Infection than other Urban Residents? Evidence from Population-Based HIV Prevalence Surveys in Kenya. Health \& Place, 18, 1144-1152. www.elsevier.com/locate/healthplace http://dx.doi.org/10.1016/j.healthplace.2012.04.003

[12] UNAIDS (2008) Report on the Global AIDS Epidemic. UNAIDS, Geneva.

[13] National AIDS Control Organization (NACO) (2005) UNGASS India Report: Progress Report on the Declaration of Commitment on HIV/AIDS, United Nations General Assembly Special Session on HIV/AIDS. NACO, Ministry of Health and Family Welfare, Government of India, New Delhi.

[14] Gupta, K., Arnold, F. and Lhungdim, H. (2009) Health and Living Conditions in Eight Indian Cities. National Family Health Survey (NFHS-3), 2005-06. International Institute for Population Sciences, Mumbai, ICF Macro, Calverton. 
[15] Manjrekar, S., Sherkhane, M. and Chowti, J. (2014) Perceptions and Outlook towards among Reproductive Age Group of Urban Slum Population. International Journal of Medical Science and Public Health, 3, 808-812.

[16] Bhatia, V., Swami, H.M. and Kaur, A.P. (2004) An Intervention Study to Enhance AIDS Awareness among Underprivileged Population in Chandigarh. Indian Journal of Dermatology, Venereology \& Leprology, 70, 87-91.

[17] Ghosh, J., Wadhwa, V. and Kalipeni, E. (2009) Vulnerability to HIV/AIDS among Women of Reproductive Age in the Slums of Delhi and Hyderabad, India. Social Science \& Medicine, 68, 638-642. http://dx.doi.org/10.1016/j.socscimed.2008.11.023

[18] Wadgave, H.V. (2011) Knowledge of HIV/AIDS Transmission among the Adolescent Girls in Slum Areas. Indian Journal of Sexually Transmitted Diseases and AIDS, 32, 139-141. http://dx.doi.org/10.4103/0253-7184.85435

[19] (1998) Report of Rapid Household Survey of RCH by Govt. of India \& Taleem Research Foundation, Ahmedabad.

[20] Zaman, F.A., Sheikh, S. and Zaman, G.S. (2013) Health Education Intervention on HIV/AIDS among the Urban slum Dwellers of Dibrugarh, Assam. Journal of Evolution of Medical and Dental Sciences, 2, 2635-2642.

[21] Durongritichai, V. (2012) Knowledge, Attitudes, Self-Awareness, and Factors Affecting HIV/AIDS Prevention among Thai University Students. Southeast Asian Journal of Tropical Medicine and Public Health, 43, 1502-1511.

[22] Nketiah-Amponsah, E. and Affual-Mensah, G. (2013) A Review of HIV/AIDS Awareness and Knowledge of Preventive Methods in Ghana. African Journal of Reproductive Health, 17, 69-82.

[23] Lowndes, C.M., Alary, M., Belleau, M., et al. (2008) West Africa HIV/AIDS Epidemiology and Response Synthesis. Characterization of the HIV Epidemic and Response in West Africa: Implications for Prevention. World Bank, Washington DC.

[24] International Institute for Population Sciences (IIPS) and Macro International (2007) National Family Health Survey (NFHS-3), 2005-06. Vol. II, India.

[25] Adedimeji, A.A., Omololu, F.O. and Odutolu, O. (2007) HIV Risk Perception and Constraints to Protective Behaviour among Young Slum Dwellers in Ibadan, Nigeria. Journal of Health, Population, and Nutrition, 25, 146-157.

[26] HIV Sentinel Surveillance 2012-13 (2012) Technical Brief. National AIDS Control Organization, Ministry of Health \& Family Welfare, New Delhi.

[27] National Summary Report-India (2011) Integrated Behavioural and Biological Assessment (IBBA), Round 2 (2009-2010). Indian Council of Medical Research and FHI 360, New Delhi.

[28] Saggurti, N., Mahapatra, B., Swain, S.N. and Jain, A.K. (2011) Male Migration and Risky Sexual Behavior in Rural India: Is the Place of Origin Critical for HIV Prevention Programs? BMC Public Health, 11, S6. http://dx.doi.org/10.1186/1471-2458-11-S6-S6 